\title{
Necessary but challenging: Multiple disciplinary approaches to solving conservation problems
}

\author{
Melissa Dick ${ }^{\mathrm{a} \dagger}$, Andrew M. Rous ${ }^{\mathrm{a} \dagger}$, Vivian M. Nguyen ${ }^{\mathrm{a}}$, and Steven J. Cooke ${ }^{\mathrm{ab} \star}$ \\ ${ }^{a}$ Fish Ecology and Conservation Physiology Laboratory, Department of Biology, Institute of \\ Environmental Science, Carleton University, 1125 Colonel By Dr., Ottawa, ON K1S 5B6, Canada, \\ ${ }^{b}$ Canadian Centre for Evidence-Based Conservation and Environmental Management, Carleton \\ University, 1125 Colonel By Dr., Ottawa, ON K1S 5B6, Canada \\ *steven cooke@carleton.ca \\ ${ }^{\dagger}$ Denotes equal contribution.
}

\section{OPEN ACCESS}

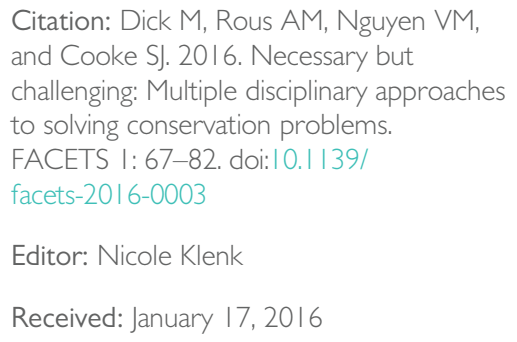

Editor: Nicole Klenk

Received: January 17, 2016

Accepted: April 12, 2016

Published: June 22, 2016

Corrected: May 24, 2017

Copyright: (C) 2016 Dick et al. This work is licensed under a Creative Commons Attribution 4.0 International License (CC BY 4.0), which permits unrestricted use, distribution, and reproduction in any medium, provided the original author(s) and source are credited.

Published by: Canadian Science Publishing

\begin{abstract}
Contemporary conservation problems are typically positioned at the interface of complex ecological and human systems. Traditional approaches aiming to compartmentalize a phenomenon within the confines of a single discipline and failing to engage non-science partners are outmoded and cannot identify solutions that have traction in the social, economic, and political arenas in which conservation actions must operate. As a result, conservation science teams must adopt multiple disciplinary approaches that bridge not only academic disciplines but also the political and social realms and engage relevant partners. Five reasons are presented that outline why conservation problems demand multiple disciplinary approaches in order to move forward because: (i) socio-ecological systems are complex, (ii) multiple perspectives are better than one, (iii) the results of research must influence practice, (iv) the heterogeneity of scale necessitates it, and (v) conservation involves compromise. Presenting reasons that support multiple disciplinarity demands a review of the barriers that impede this process, as we are far from attaining a model or framework that is applicable in all contexts. Two challenges that impede multiple disciplinarity are discussed, in addition to pragmatic solutions that conservation scientists and practitioners can adopt in their work. Overall, conservation researchers and practitioners are encouraged to explore the multiple disciplinary dimensions of their respective realms to more effectively solve problems in biodiversity and sustainability.
\end{abstract}

Key words: socio-ecological, transdisciplinary, interdisciplinary, complex systems, biodiversity

\section{Introduction}

Humans are dominating the globe (Vitousek et al. 1997) and with that has come unprecedented loss of biodiversity and dramatic alterations in ecosystem function (Naeem 2002; Hooper et al. 2012). Indeed, some argue that we are now entering a new era-the Anthropocene (Steffen et al. 2007; Zalasiewicz et al. 2011). Despite many small victories, often focused on a fine scale (e.g., single population, localized site), conservation science may be losing the war on the global scale (Butchart et al. 2010). Regardless of the commitment of most governments to reduce the rate and extent of ecosystem degradation, population decline, and species loss, issues such as climate change, overexploitation of natural resources, habitat loss, and invasive species continue to undermine the goal of conservation science, which is to concomitantly maximize benefits to biodiversity and to people (Kareiva and Marvier 2012). Today, conservation 
science is defined as a broad multiple disciplinary ${ }^{1}$ field that incorporates many disciplines (and associated concepts, knowledge, and approaches), such as biology, geography, ecology, public policy, philosophy, economics, sociology, and communications. This differs somewhat from Soulé's (1985) multidisciplinary perspective on conservation biology, which was largely focused on biodiversity and its loss, maintenance, and restoration, with an acknowledgement of socioeconomic influences, rather than placing humans and human behaviour at the forefront (Sandbrook et al. 2013). This new paradigm of conservation research (Luks and Siebenhüner 2007; Sandbrook et al. 2013) requires conservation problems to be framed simultaneously in both natural and socioeconomic dimensions.

In recent years, multiple disciplinary research has gained recognition and support (Gewin 2014) through the establishment of dedicated funds (i.e., the US National Science Foundation and Research Councils UK), the emergence of new institutes that offer programs that cut across traditional disciplinary boundaries, and is listed in university mission statements, course curricula, and in some cases, considered an asset when hiring new faculty members (Klein 2000). Indeed, multiple disciplinarity (and all the associated terms: inter-, multi-, and transdisciplinarity) is arguably a conservation science buzzword of our times, and as a result, it has also garnered some criticism. Some argue that the concept is undergoing abuse due to the encouragement by governments and other institutions of multiple disciplinary research seemingly for its own sake. We challenge this view and argue that multiple disciplinary research, specifically in a conservation science context, is more than an administrative label. Multiple disciplinarity not only defines conservation science, but also holds the key to producing research findings that are relevant and applicable. We do not intend to argue that all conservation problems require a multiple disciplinary approach. In fact, we only encourage multiple disciplinary approaches when the problem truly demands it, not just for the sake of applying one of the multiple disciplinary labels. Building a multiple disciplinary team by simply "checking the box" for each discipline is unlikely to lead to successful integration (Caudill and Roberts 1951; Lynch 2006). Conservation science is necessarily a multiple disciplinary endeavour, and we contend that contemporary scholars able to bridge fields of research and various political and social elements will be best equipped for solving conservation problems.

Much scholarly activity has focused on defining and discussing the terms used to describe the different levels or types of integrated research (Kockelmans 1979; Max-Neef 2005; Tress et al. 2005; Stock and Burton 2011). For the sake of brevity and inclusivity, we will use the term "multiple disciplinary research" to describe all types of crossing and integration between/among disciplines and nonacademic institutions (Pooley et al. 2014).

Although there is an established literature addressing the issue of how to conduct multiple disciplinary research (including a new framework; see Pooley et al. 2014), there is relatively little written on why it is important to continue pursuing this path in a conservation science context. Although there are a growing number of incentives to conduct multiple disciplinary research, there remains a gap in the level of career advancement it can offer. This is particularly important because engaging in multiple disciplinary activities can be negatively perceived as hindering one's career due to the demand for large time investments with little immediate rewards, and for venturing into an area where their expertise may not be as easily identified (Rhoten and Parker 2004). As such, we present five reasons why a multiple disciplinary approach to solving conservation problems is essential (Fig. 1), followed by two major challenges that continue to deter the use of multiple disciplinary approaches. The primary goal is to highlight the key benefits associated with multiple disciplinary research in understanding the dynamics of conservation problems in a socio-ecological context. We do not pretend that the ideas we present

${ }^{1}$ For the purpose of this manuscript, we adopt the terminology of Pooley et al. (2014) whereby multiple disciplinary is used to encompass multidisciplinary, interdisciplinary, and transdisciplinary approaches. These individual terms for multiple disciplinarity can be defined individually (see Klein 2000; Tress et al. 2005). 


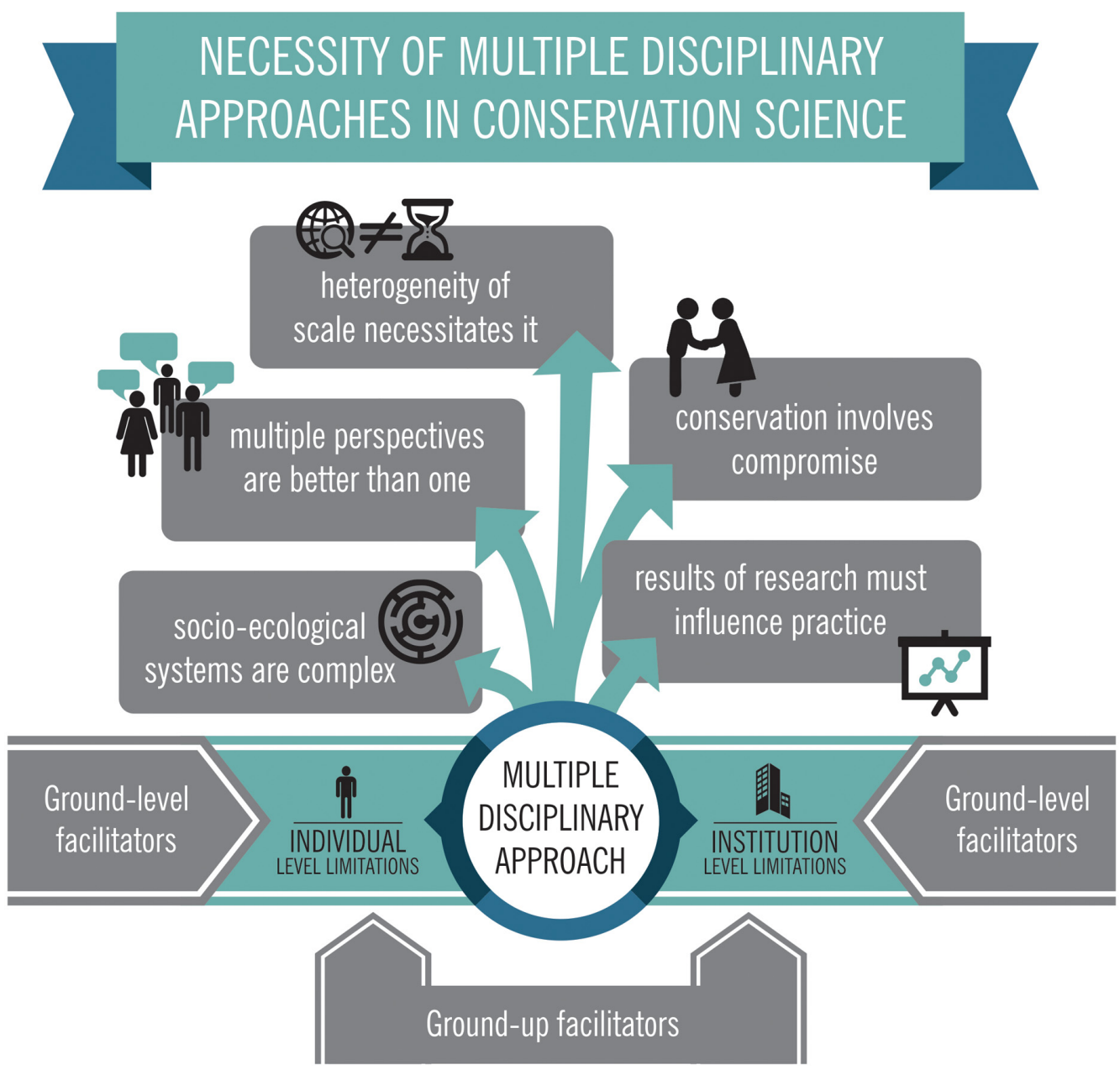

Fig. 1. Infographic synthesizing why conservation problems demand multiple disciplinary approaches with the limitations present, and considerations to overcoming these limitations to solve conservation problems.

here are entirely novel, but to our knowledge, they have not been presented in a cohesive single paper. Here, we provide a short perspective article that synthesizes relevant literature that argues for reasons why multiple disciplinary approaches are necessary in conservation science and practical ways to achieve multiple disciplinarity. The intended audience is broad, but our thinking was somewhat framed around the notion that it will be the next generation-today's early career researchers-that need to be prepared to engage in multiple disciplinary research and thinking to address the pressing conservation problems of today and tomorrow (Chapman et al. 2015).

\section{Why are multiple disciplinary approaches necessary in conservation science?}

\section{Because socio-ecological systems are complex}

Conservation biology was first described as a crisis discipline (Soulé 1985). The "wicked problems" in conservation science (e.g., climate change, global biodiversity decline) (Kareiva and Marvier 2012) are extremely complex (Rittel and Webber 1973). Very few of these problems lie solely within the bounds of one discipline (Daily and Ehrlich 1999). Traditionally, researchers have used disciplinarity as a way 
of reducing the complexity of these problems in order to approach them in isolation. It is naive for conservation researchers, no matter their training, to think that they can reach a deep understanding of an entire conservation problem, and thus propose an effective solution, simply by examining a singular component of the problem (Box 1). We do not argue that the complex interactions even within a single discipline (i.e., biologists studying the interactions between organisms and their environment) are not important, but rather that to solve complex conservation problems, a holistic understanding of the full interactions (e.g., biotic, abiotic, and socioeconomic) is necessary. The vast majority of our ecosystems are human-dominated (Vitousek et al. 1997), and as a result, it is impossible to address conservation problems without fully acknowledging the human dimension (Mascia et al. 2003; Fox et al. 2006; Kareiva and Marvier 2012; Bennett and Roth 2015). A solution to complex problems such as global biodiversity decline is unlikely to be successful solely by understanding the ecological drivers of decline, but is likely to require a holistic approach that incorporates the complex interaction between the ecological, socioeconomic, and political forces (Mallegowda 2013; Sandbrook et al. 2013). Researchers must take the time to explore and build frameworks that do not rely on removing the complexity of a problem, but rather collaboratively design synthetic frameworks that enable understanding of complex interactions between the environment, society, and policy.

Box 1. Examples of conservation success stories, with particular emphasis on why multiple disciplinary approaches were necessary to solve conservation problems.

\section{Because socio-ecological systems are complex}

Degradation in protected areas-It is generally accepted that animal populations are better conserved in areas that have been designated for protection. Unfortunately, this simplistic relationship is rarely realized because of complex human-ecological relationships. The Wolong Nature Reserve was established in 1975 to protect high-quality habitat in Southwestern China for the endangered Giant Panda. Human activities in the reserve include agriculture, fuel wood collection, and ecotourism. Analysis of forest cover and connectivity pre- and post-establishment of the reserve revealed increased fragmentation and a higher rate of loss of high-quality Giant Panda habitat due to an unexpected rapid increase in the human population size within the reserve (Liu et al. 2001). China's former one-child policy did not apply to members of the minority ethnic groups that comprised nearly three-quarters of the local population in the reserve (Liu et al. 1999). A shift in lifestyle where more young adults established new households rather than remaining in traditional multigenerational households and expanded economic opportunities from tourism further compounded the human impacts on the Giant Panda habitat. In recognition of the complex human-ecological interactions in the reserve, the Chinese government introduced several conservation programs to protect and restore high-quality habitat, including a forest conservation program where locals monitor illegal harvesting, a hydropower station to reduce dependency on fuel wood, and a program to reforest cropland with plantations (Liu et al. 2007). These conservation levels have achieved varied levels of success, as researchers continue to explore humanwildlife interactions in this complex socio-ecological system.

\section{Because multiple perspectives are better than one}

Conservation of endemic Mahseers-India's endemic Mahseers are a religiously, culturally, recreationally, and economically important fish. They form the cornerstone of an emerging recreational fishery in many regions of India. However, several species are listed as threatened or endangered. Primary threats include habitat degradation and loss, as a result of river fragmentation and resource extraction, and overexploitation, including both poorly regulated or non-existent fishing regulations and illegal fishing methods (Gupta et al. 2015). Even though these fish have been a part of the livelihoods of local communities for centuries and the target of angler and naturalists for over a hundred years, basic population biology, ecology, and taxonomy is poorly resolved, making it difficult to reliably assess the status of these fishes and develop strategies to conserve them and their habitat (Gupta et al. 2015). In spite of uncertainty, conservation scientists, practitioners, and local parties have increased habitat protection, initiated habitat restoration, and promoted responsible catch and release angling techniques to sustain wild stocks of Mahseers (Gupta et al. 2015). However, growing conflicts between recreational anglers, poorly defined government organizations, and other activities (e.g., hydro development) require multifaceted stakeholder engagement and commitment to ensure the sustainable development and conservation of these fishes. It will require deeper ecological understanding, 
political commitment, and engagement between many local communities and state government organizations. Because both their importance and their threats are so diverse, no single perspective could possibly capture all the nuanced value these fish have for sport, culture, economic growth, and sustaining livelihoods.

\section{Because the results of research must influence practice}

Declining avian abundance due to agriculture - In the last quarter of the 20th century, the British Trust for Ornithology (BTO) identified a decline in numbers of farmland bird species in the UK. For decades, this issue remained largely unknown to most members of the public, farmers, and politicians. The BTO sought to protect these birds by influencing farmland practices and policies and by increasing the public's understanding of the causes of the declines. The scientifically rigorous design and analysis of their monitoring and modeling programs, their active links with policymakers and conservation practitioners, and their ability to communicate with the wider community through their thousands of volunteer fieldworkers allowed the BTO to increase public awareness of this issue and to reach consensus that something had to be done. Ultimately, these multiple avenues of communication and interaction allowed for the science to translate to policy and to a commitment by the government to halt the declines (Greenwood 2003). Since the beginning of the 21st century, multiple agricultural policy measures have been developed with wildlife conservation in mind, several species of agricultural birds, and some agricultural habitats are now the subject of the UK's Biodiversity Action Plan, and "diversity and abundance of wildlife resources" is included in the top five things that the Department of Environment, Food and Rural affairs aims to promote.

\section{Because the heterogeneity of scale necessitates it}

Effects of marine renewable energy projects assessed over spatiotemporal scales-Marine renewable energy devices (MREDs) such as offshore wind, wave, and tidal-current energy converters are new ways of deriving energy from the sea. In light of increasing concerns over global climate change and the need to reduce the use of fossil fuels, MREDs will be ready for distribution on commercial scales soon. However, concerns exist about the ecological effects of such energy projects on the surrounding marine flora and fauna. Past studies on this subject have focused on species of interest, especially megafauna such as birds and marine mammals, and have not considered long-term consequences of the construction or decommission of a MRED. This study adopts a broader approach in studying the consequences of MREDs for benthic flora and fauna across a variety of scales (Miller et al. 2013). The study aimed to measure the demands that MREDs require as a function of the sum of the effects of the project installation, maintenance of the array, decommission and any additional cumulative effects on the ecology of the benthic environment (Miller et al. 2013). This approach allowed for an investigation across biological scales (epibenthic communities, mobile species, and habitat availability), abiotic scales (sedimentation patterns and accelerating and decelerating flow fields), and temporal scales (construction, operation, and decommission). This study resulted in a comprehensive analysis of the overall sustainability of MREDs across space and time and aided in understanding the magnitude of the ecological response during the life cycle of an MRED relative to other human-related disturbances (Miller et al. 2013).

\section{Because conservation involves compromise}

Multiple uses of the Great Barrier Reef Marine Park-The Great Barrier Reef Marine Park (GBRMP) was created in 1975 to protect one of the most diverse and complex natural systems on earth. It is widely considered a global benchmark for conserving marine ecosystems. The GBRMP applies a multiple-use zoning approach to regulate the protection of biodiversity whilst permitting wise and reasonable use of the area (Day 2002). A management plan that completely restricts access or extractive uses is unlikely to garner public support. The approach identifies and enforces multiple spatial zones with varying levels of protection and recreational and commercial use. Further still, the Representative Areas Program was created to re-zone the park in a manner that would further protect the diversity of ecosystems in the park, beyond just coral reefs. This network of no-take areas now encompasses more the $33 \%$ of the GBRMP (increase from 4.5\%), where at least $20 \%$ of each bioregion is now protected under no-take areas (Fernandes et al. 2005). The approach in GBRMP allows some compromise to accommodate people's diverse uses and values. When these uses can frequently compete and displace one another, there has been a need to find equitable use and fair access to resources by soliciting public involvement, early stakeholder engagement, and diverse and representative steering committees. Separating conflicting uses, keeping ecologically or culturally sensitive areas free of use, and allowing for appropriate transition zones between different zones has successfully mediated conflict in this multiple-use marine protected area (Day 2002). 


\section{Because multiple perspectives are better than one}

Most researchers are trained by institutions to be experts within their discipline. Traditional disciplinary approaches are beneficial insofar as providing frames of reference, methodologies, theories, and tools. However, when faced with, often unpredictable, conservation problems that involve complex socio-ecological systems, researchers must abandon the status quo of analyzing a question from within their disciplinary silo. No discipline has intellectual precedence in an endeavour as important as solving conservation problems (Hadorn et al. 2006). It is paramount that conservation researchers are cognizant of how their expertise fits within the larger conservation context (Box 1). Conservation researchers must commit to both working collaboratively as part of multiple disciplinary teams, and learning and integrating multiple disciplinarity within their own approaches to conservation science. Doing so can expand a researcher's perspective in such a way that can foster future creativity and lead to integrative approaches to solving conservation problems (Andrade et al. 2014). Conservation researchers with expertise in or familiarity with social sciences will have more traction in the social, economic, and political worlds (Gibbs et al. 2008). Even though criticism exists that multiple disciplinary work lowers productivity in career paths (Brewer 1999; Roy et al. 2013), we argue that the benefits of multiple disciplinary approaches to an individual problem promote ongoing learning outside one's own area of expertise (see Kurland et al. 2010, for example); therefore, diversifying and enhancing one's own perspective, knowledge, and career satisfaction (Demerouti et al. 2001; Amey and Brown 2005; Miller et al. 2008).

\section{Because the results of research must influence practice}

In other fields, an integration of methods, approaches, and perspectives may suffice in achieving multiple disciplinary research goals. However, in conservation, the results of research must generate effective, evidence-based policies that enable action (Sutherland et al. 2004). Such efforts demand collaboration with policymakers, conservation managers, and stakeholders outside of the academic realm (Box 1). Putting the results of research into action is what matters most, yet it is the biggest challenge that any practicing conservationist faces (Gibbs et al. 2008). Providing management recommendations that are applicable in reality requires the use of effective knowledge systems that help bridge the gap between knowledge and action by facilitating communication, translation, and mediation across boundaries (Cash et al. 2003). Successful systems that mobilize science and technology for sustainability are characterized by the involvement of boundary organizations that aid in knowledge mobilization, promoting communication and translation, and enhancing the salience, credibility, and legitimacy of the information produced (Cash et al. 2003). Major advances in conservation action will take place not in scientific laboratories or field research sites, but in the political and economic arenas because current limitations in conserving biodiversity are not due to lack of knowledge, but rather poor implementation (Meffe and Viederman 1995). The need for scientific results to impact practice, therefore, demands not only a traditional interdisciplinary approach that can be defined in an academic context, but also a multiple disciplinary approach that spans the boundaries of policy and management and engages partners, stakeholders, and other non-scientists (Miller et al. 2008). The foundation of a knowledge system for sustainability cannot be built within the boundaries of one discipline, or within the boundaries of academia alone.

\section{Because the heterogeneity of scale necessitates it}

Many of the problems encountered by societies in managing natural resources arise because there is a mismatch between the scale of the ecological process in question and the scale of management (Cumming et al. 2006). Working across scales to understand mechanisms underlying conservation problems is the norm (Cooke et al. 2014). Many different scales are relevant in defining conservation questions, including biological, spatial, temporal, jurisdictional, and institutional, among others (Cash et al. 2006; Cooke et al. 2014). However, in conservation science, the scale at which we can measure 
something is rarely at the same scale as the consequences of interest (Cooke et al. 2014). For example, it is very challenging to monitor the population status of organisms that are rare (or cryptic) yet have a broad distribution while trying to identify the mechanisms (including site-specific and more regional or global processes) behind any changes in population trajectories. Although the biological scale may be concerned with genes, organisms, populations, communities, and ecosystems that are considered over specific levels of space and time, the relevant jurisdictional scales are, on the other hand, organized by political units such as towns, counties, states, provinces, or nations, which exist on vastly different spatiotemporal scales and have their own concerns and priorities. Reconciling these biophysical and social scales is important to improve policy and management strategies (Box 1). Failure to address the importance of scale in conservation science will impede the ability to generate scientific understanding that can contribute to meaningful and desirable outcomes, particularly in forms of policies (Cooke et al. 2014). A multiple disciplinary approach that spans both academic and non-academic boundaries can account for the seemingly abstract and intangible scales that govern the broader socioeconomic perspectives of the conservation problem at hand. The inclusion of societal and management scales allows for the addition of the dimension that designs and implements appropriate policy/management plans (which again can be very local or more global). Conservation science must be prepared to show how it is relevant at the policy/management scale, or to change the scale at which policy/management intervention is applied (Cooke et al. 2014). Accepting where a research question lies in the multidimensional and multiscalar arena of conservation science from a multiple disciplinary perspective will allow researchers to understand the big picture and will increase the applicability and level of impact of their work in different spheres ranging from local to global.

\section{Because conservation involves compromise}

Conservation researchers are required to make decisions in the face of uncertainty (Soulé 1985; Cook et al. 2010; Allen and Gunderson 2011). When conservation problems are initially identified, researchers often have little or no evidence to guide them, yet they must still act (Regan et al. 2005). As a result of the interrelationships between ecological, socioeconomic, and political components of conservation problems (Liu et al. 2007), conservation researchers must have an understanding of the trade-offs and potential unintended consequences that conservation action may have on both these social and ecological systems (Miller et al. 2012). Monitoring the outcomes of conservation actions from all perspectives (i.e., socioeconomic outcomes) can enable conservation researchers to gain more knowledge, achieve a deeper understanding of the problems, and adapt the solutions to better understand and balance the trade-offs (Box 1). This will lead to more effective, long-term conservation successes. When conservation actions are implemented, inevitably there are trade-offs that affect society. Making conservation science decisions within an adaptive management framework permits learning from management actions and further refinement of the management decisions (Walters and Holling 1990; Allen and Gunderson 2011).

\section{Why is it so challenging to conduct multiple disciplinary research?}

There is much literature that explores the challenges associated with multiple disciplinary research. Studies that trumpet multiple disciplinary approaches as succeeding in integrating disciplines and engaging policymakers in conservation science almost always include comments on the challenges that remain in engaging the social sciences and in understanding the social context of implementation (see Reyers et al. 2010). Although simple and pragmatic solutions are often offered, others suggest that a fundamental shift in the epistemological nature and philosophy of scientific knowledge is required, which may be more difficult for conservation researchers to understand and apply (Lélé and Norgaard 2005; Miller et al. 2008). Indeed, it is crucial to address the issue of how to conduct multiple disciplinary research in order to address conservation problems. Here, we focus on the practical 
solutions that researchers can readily adopt in their work to overcome barriers to multiple disciplinary research.

\section{Because languages/frameworks/cultures are distinct among disciplines}

Multiple disciplinary research brings together diverse fields and institutions that will have contrasting research paradigms defined by distinctive languages, cultures, perspectives, and methods of communication (Bracken and Oughton 2006; Evely et al. 2008; Miller et al. 2008). The barriers to multiple disciplinary research in this regard are often supported by obscure assumptions. For example, the perceived gap between natural and social scientists that exists to this day limits the effectiveness of conservation action (Fox et al. 2006). Misconceptions between groups extend into the non-academic world too, where scholars hesitate to engage with the public and policymakers due to potential communication problems and misaligned priorities. Different types of knowledge are often involved (e.g., traditional, experiential, and political knowledge), which adds new levels of complexity (Freitag 2014) and raises questions about which information can be deemed "trustworthy" (Huntington 2000; Sutherland et al. 2014). Discussion between these different parties demands a recasting of the interactions between scholar and practitioner, which undoubtedly causes tensions (Cash et al. 2003). Failure to listen to or engage stakeholders has impeded conservation on many occasions (e.g., Christie 2004; Keppel et al. 2012). In order for conservation science to produce results that can reliably support effective management practices, collaboration between all involved parties (academic and non-academic) must occur from the onset of the project. Reconciling these different definitions, priorities, perspectives, and types of knowledge is a big challenge in conducting multiple disciplinary research. Here, the involvement of "boundary organizations" or individuals capable of "boundary spanning" and who can act as intermediaries between the arenas of science and policy may be key (Cash et al. 2003; Cook et al. 2013). Instead of investing time and resources in designing a new language to communicate across disciplines, researchers or groups already positioned at the interface of two or more disciplines can bridge the gap and help translate in a common language while retaining distinct lines of accountability to both groups. Furthermore, effective communication between the scientific and practical spheres requires a revision of anticipated timelines surrounding conservation projects. Time is required to overcome the assumption of mistrust that hampers the sharing of language and knowledge (Buller 2009; Stock and Burton 2011). Also, building trusting relationships and collegiality are cited as critical to interdisciplinary success (Daily and Ehrlich 1999); however, relationships are not built overnight. Time and patience are required to develop relationships, methods and common research goals (Evely et al. 2010).

\section{Because the current institutional structure does not make it easy}

The strongest barrier to integration is the fact that traditional academic reward systems discourage multiple disciplinary collaboration and applied problem solving. Moreover, there is a lack of funding for collaborative work, limited opportunities for multiple disciplinary publishing, and lack of incentives or rewards to engage in multiple disciplinary or collaborative work (Metzger and Zare 1999; Mascia et al. 2003; Fox et al. 2006). Traditional institutional and organizational structures discourage multiple disciplinary collaboration (Fox et al. 2006) by failing to facilitate interdepartmental training and scholarship (Mascia et al. 2003; Andrade et al. 2014) and generate impediments to hiring, promotion, and recognition (Brewer 1999). Even when multiple disciplinary researchers or teams break though disciplinary boundaries, funding has been difficult (Fox et al. 2006) and time-consuming to secure (Roy et al. 2013), largely because decisions for funding support remain bounded within single disciplines (Metzger and Zare 1999), although this is improving (Campbell 2005; Lynch 2006). Lastly, multiple disciplinary researchers have limited avenues to publish their work. Numerous authors have expressed that interdisciplinary journals are viewed as "young" and less reputable than established 
single disciplinary journals (Daily and Ehrlich 1999; Campbell 2005; Roy et al. 2013). Moreover, it can be difficult for editors to identify and secure appropriate referees who are able to review multiple disciplinary work. Not all researchers understand (e.g., they themselves only work in one discipline and do not have experience to assess work that crosses boundaries) or accept the premise of multiple disciplinary research (e.g., viewed as being too general given lack of disciplinary depth or fail to value such work) and do so with a limited respect. However, Naiman (1999) contends that most of the obstacles actually lie within the group (i.e., lack of trust among team members) rather than within the publication and peer review system. Despite the barriers posed by the current academic structure, there is growing sentiment that multiple disciplinary researchers are slowly overcoming these obstacles in pursuit of a holistic approach to conservation science [see Chapman et al. (2015) for a forward-looking viewpoint].

\section{Paths forward: facilitating multiple disciplinarity}

In light of the demand for multiple disciplinary approaches for conservation and the challenges associated with engaging in such activities, we propose a general framework with considerations for facilitating multiple disciplinarity in conservation science. This framework and its considerations are intentionally broad and not prescriptive as every conservation problem or question is context specific. From our perspective, there are several key limitations that need to be overcome or addressed to engage in multiple disciplinarity. There are limitations at the individual level (Fig. 1), which are challenges that are concerned with personal characteristics and social dimensions, such as relationship building, building trust, capacity and ability to work as a team, willingness to commit time and energy into learning a new language or culture, open-mindedness, social awareness, and motivation and interest in engaging with others particularly those from other backgrounds. There are also limitations at the institutional level (Fig. 1) such as institutional structures that do not make it easy to engage in multiple disciplinarity, or the silos created in institutions that emphasize greater cultural differences. To engage in multiple disciplinarity, it is necessary to function within the limitations of the individual and institutional levels.

In general, recommendations for improving multiple disciplinary approaches have been poorly represented in the literature, although widely discussed in forums such as Twitter. It also appears that we are just entering an era where examples are beginning to appear in the literature. With that in mind, we put forth considerations (based on the literature to date) that may help to break down the limitations that exist to achieve multiple disciplinarity. We categorize these considerations as ground-up facilitators, which are considerations that can be invested in a priori to functioning in a multiple disciplinary realm, and ground-level facilitators, which are considerations that can be actioned simultaneously to multiple disciplinary functioning (Fig。 1).

Ground-up facilitators function to lessen the current individual and institutional limitations such as providing training to students or professional development for practitioners and decision makers to foster development of a multiple disciplinary skill set. One example is through experiential education in a field course such as the one in Tambopata National Reserve and Bahuagja Sonene National Park in the Department of Madre de Dios, Peru (Landon et al. 2015). The course was designed to teach students how to effectively engage with and learn from scholars and practitioners with different disciplinary backgrounds. Other considerations for ground-level facilitators can be instituting innovative reward structures and incentives to help break down the current academic "publish or perish" culture (see Schäfer et al. 2011) and foster more collaborative environment in the institutional structures. There is a strong push for change in the traditional established disciplinary structure of universities, and the 21 st century will probably see new and possibly localized, organizational mix of disciplinary departments, interdisciplinary centres, and new disciplines (Garrett-Jones 2009, 191). Some private organizations use approaches such as requiring their employees to change work desks periodically 
to foster relationship building and breakdown silos with the purpose of fostering innovation or provide informal spaces within workplaces to facilitate interaction.

Ground-level facilitators function to facilitate the process of multiple disciplinarity and are particularly useful once the process of multiple disciplinarity has started. These ground-level facilitators can include brokers or third-party facilitators whose role is to mediate the interactions of the various actors involved (Strang 2009). For example, the Learning for Sustainability Network provides tools to help facilitate integration and collaboration (http://learningforsustainability.net/). A popular lesson in the literature is "finding a common ground" or a "common language". The Baltic Sea Research Programme (BIREME) of the Academy of Finland provides an excellent example of interdisciplinary research that has yielded lessons learned. From this program, Haapasaari et al. (2012) found that their common ground or language was a methodology, which were Bayesian belief networks. This methodological approach was situated in no-one's land and bridged three conceptually different fields of social science, biology, and economics to better understand the complexity of the Baltic salmon fisheries. Similarly, an interdisciplinary team, investigating scarce brackish water that was causing problems with cultivating crops, agreed that a common language was needed for the success of the project. Here, ecohydrologists and agricultural economists from Wageningen University found their common language to be mathematics and found quantitative models to be an easy common ground to engage in interdisciplinary cooperation (Ben-Gal et al. 2013). A common ground or language can also be found in a common goal. Setting a global goal can facilitate the integration of various disciplines. Griggs et al. (2013) in Nature argued for new sustainable development goals (SDGs) for 2030 that integrate planetary boundaries and stability, which may potentially be drivers for transdisciplinary research and education.

Because the world is complex, it may require multiple disciplinary centres/institutions to be created, where expert individuals who possess multiple disciplinary skillsets (e.g., collaborative skills, patience, and social awareness) are recruited to advance conservation. Centres may be part of an academic institution such as the Integrative Research Institute on Transformations of Human-Environment Systems (IRI THESys; https://www.iri-thesys.org/), or "Transdisciplinary Hubs" at Brock University in Canada (https://www.brocku.ca/trans-disciplinary-research). The Research Institute for Humanity and Nature (RIHN; http://www.chikyu.ac.jp/rihn_e/about.html) is an inter-university research institute established in 2001 that conducts integrated research in global environmental studies with the goal to conduct research that will resolve global environmental problems. Governments may also create multiple disciplinary centres, such as the Transdisciplinary Research Integration Centre (http://systemsresilience. org/index-e.html) in Japan, which was created to improve systems resilience after the 3.11 Tohoku earthquake in 2011. Ideally, joint government-university and (or) public-private partnerships may assist in facilitating multiple disciplinary research as outlined in the Advancing Research In Science and Engineering (ARISE) II report by the American Academy of Arts and Sciences published in 2013 (www.amacad.org/arise2), which describes a new playing field where the public and private sectors and academia play a new role and need to adapt to new worldwide economic realities and to societal challenges that are global, complex, interconnected, and urgent.

\section{Conclusion}

By necessity, conservation science has been shaped into a multiple disciplinary field that addresses coupled human-ecological systems. The literature is replete with conceptual articles on how to conduct multiple disciplinary research, whereas there are fewer attempts to identify distinct reasons why multiple disciplinary research approaches are necessary in conservation science. We argue that multiple disciplinary approaches are necessary in conservation science because (i) socio-ecological systems are complex, (ii) multiple perspectives are better than one, (iii) results of research must impact upon practice, (iv) the heterogeneity of scale necessitates it, and (v) conservation involves compromise. Although we offer reasons for why multiple disciplinary research approaches are 
necessary, we fully recognize that there are several practical challenges in doing so. We provide a forward-looking perspective and framework on strategies for facilitating multiple disciplinarity recognizing the need for action by individuals and organizations and mechanisms that operate as ground-level facilitators and ground-up facilitators. The framework is not intended to be prescriptive but rather to provide examples of ideas that have worked for others and may have relevance to your particular context. Conservation researchers must adopt a broad perspective that combines basic biological sciences and its application in ecological systems with a human-centered focus on economics, politics, law, and communication which together comprise the political arena in which all conservation efforts must operate (Gibbs et al. 2008). We hope that this paper serves as a foundation to motivate conservation researchers, especially those in training (see Chapman et al. 2015), to address the multiple disciplinary interactions of complex conservation problems necessary to help solve complex conservation problems.

\section{Acknowledgements}

MD and VMN are supported by NSERC graduate fellowships. SJC is supported by the NSERC Discovery Grants program and the Canada Research Chairs Program. We thank A. Cuan for his help constructing the infographic. We thank our colleagues and several anonymous referees for providing feedback on some of the ideas developed here.

\section{Author contributions}

Conceived and designed the study: MD, AMR, VMN, SJC. Contributed resources: SJC. Drafted or revised the manuscript: MD, AMR, VMN, SJC.

\section{Competing interests}

SJC is currently serving as a Subject Editor for FACETS, but was not involved in review or editorial decisions regarding this manuscript.

\section{Data accessibility statement}

All relevant data are within the paper.

\section{References}

Allen CR, and Gunderson LH. 2011. Pathology and failure in the design and implementation of adaptive management. Journal of Environmental Management, 92: 1379-1384. doi:10.1016/j. jenvman.2010.10.063.

Amey MJ, and Brown DF. 2005. Interdisciplinary collaboration and academic work: a case study of a university-community partnership. New Directions for Teaching and Learning, 2005(102): 23-35. doi:10.1002/tl.194.

Andrade K, Corbin C, Diver S, Eitzel MV, Williamson J, Brasheres J, and Fortmann J. 2014. Finding your way in the interdisciplinary forest: notes on educating future conservation practitioners. Biodiversity and Conservation, 23(14): 3405-3423. doi:10.1007/s10531-014-0818-z.

Ben-Gal A, Weikard H-P, Shah SHH, and van der Zee SEATM. 2013. A coupled agronomiceconomic model to consider allocation of brackish irrigation water. Water Resources Research, 49(5): 2861-2871. doi:10.1002/wrcr.20258.

Bennett NJ, and Roth R (eds.). 2015. The conservation social sciences: what?, how? and why? Canadian Wildlife Federation and Institute for Resources, Environment and Sustainability, University of British Columbia, Vancouver, BC. doi:10.13140/2.1.2664.3529. 
Bracken LJ, and Oughton EA. 2006. 'What do you mean?' The importance of language in developing interdisciplinary research. Transactions of the Institute of British Geographers, 31(3): 371-382. doi:10.1111/j.1475-5661.2006.00218.x.

Brewer GD. 1999. The challenges of interdisciplinarity. Policy Sciences, 32(4): 327-337. doi:10.1023/ A:1004706019826.

Buller H. 2009. The lively process of interdisciplinarity. Area, 41(4): 395-403. doi:10.1111/ j.1475-4762.2008.00856.x.

Butchart SH, Walpole M, Collen B, van Strien A, Scharlemann JPW, Almond REA, Baillie JEM, Bomhard B, Brown C, Bruno J, Carpenter KE, Carr GM, Chanson C, Chenery AM, Csirke J, Davidson JN, Dentener F, Foster M, Galli A, Galloway JN, Genovesi P, Gregory RD, Hockings M, Kapos V, Lamarque J-F, Leverington F, Loh J, McGeoch MA, McRae L, Minaysan A, Hernández Morcillo M, Oldfield TEE, Pauly D, Quader S, Revenga C, Sauer JR, Skolnik B, Spear D, Stanwell-Smith D, Stuart SN, Symes A, Tierney M, Tyrrell TD, Vié J-C, and Watson R. 2010. Global biodiversity: indicators of recent declines. Science, 328(5982): 1164-1168. doi:10.1126/ science.1187512.

Campbell LM. 2005. Overcoming obstacles to interdisciplinary research. Conservation Biology, 19(2): 574-577. doi:10.1111/j.1523-1739.2005.00058.x.

Cash DW, Adger WN, Berkes F, Garden P, Lebel L, Olsson P, Pritchard L, and Young O. 2006. Scale and cross-scale dynamics: governance and information in a multilevel world. Ecology and Society, 11(2): 8 [online]: Available from http://www.ecologyandsociety.org/vol11/iss2/art8/.

Cash DW, Clark WC, Alcock W, Dickson NM, Eckley N, Guston D, Jager J, and Mitchell R. 2003. Knowledge systems for sustainable development. Proceedings of the National Academy of Sciences of the United States of America, 100(14): 8086-8091. doi:10.1073/ pnas. 1231332100 .

Caudill W, and Roberts BH. 1951. Pitfalls in the organization of interdisciplinary research. Human Organization, 10(4): 12-15. doi:10.17730/humo.10.4.088p7235564556x1.

Chapman JM, Algera D, Dick M, Hawkins EE, Lawrence MJ, Lennox RJ, Rous AM, Souliere CM, Stemberger HLJ, Struthers DP, Vu M, Ward TD, Zolderdo AJ, and Cooke SJ. 2015. Being relevant: practical guidance for early career researchers interested in solving conservation problems. Global Ecology and Conservation, 4: 334-348. doi:10.1016/j.gecco.2015.07.013.

Christie P. 2004. Marine protected areas as biological successes and social failures in Southeast Asia. American Fisheries Society Symposium, 42: 155-164.

Cook CN, Hockings M, and Carter RW. 2010. Conservation in the dark? The information used to support management decisions. Frontiers in Ecology and the Environment, 8(4): 181-186. doi:10.1890/090020.

Cook CN, Mascia MB, Schwartz MW, Possingham HP, and Fuller RA. 2013. Achieving conservation science that bridges the knowledge-action boundary. Conservation Biology, 27(4): 669-678. doi:10.1111/cobi.12050.

Cooke SJ, Killen SS, Metcalfe JD, McKenzie DJ, Mouillot D, Jørgensen C, and Peck MA. 2014. Conservation physiology across scales: insights from the marine realm. Conservation Physiology, 2(1): 1-15. doi:10.1093/conphys/cou024. 
Cumming GS, Cumming DHM, and Redman CL. 2006. Scale mismatches in social-ecological systems: causes, consequences, and solutions. Ecology and Society, 11(1): 14 [online]: Available from http://www.ecologyandsociety.org/vol11/iss1/art14/.

Daily GC, and Ehrlich PR. 1999. Managing Earth's ecosystems: an interdisciplinary challenge. Ecosystems, 2(4): 277-280. doi:10.1007/s100219900075.

Day JC. 2002. Zoning-lessons from the Great Barrier Reef Marine Park. Ocean and Coastal Management, 45(2-3): 139-156. doi:10.1016/S0964-5691(02)00052-2.

Demerouti E, Bakker AB, de Jonge J, Janssen PP, and Schaufeli WB. 2001. Burnout and engagement at work as a function of demands and control. Scandinavian Journal of Work, Environment and Health, 27(4): 279-286. doi:10.5271/sjweh.615.

Evely AC, Fazey I, Lambin X, Lambert E, Allen S, and Pinard M. 2010. Defining and evaluating the impact of cross-disciplinary conservation research. Environmental Conservation, 37(4): 442-450. doi:10.1017/S0376892910000792.

Evely AC, Fazey I, Pinard M, and Lambin X. 2008. The influence of philosophical perspectives in integrative research: a conservation case study in the Cairngorms National Park. Ecology and Society, 13(2): 52 [online]: Available from http://www.ecologyandsociety.org/vol13/iss2/art52/.

Fernandes L, Day J, Lewis A, Slegers S, Kerrigan B, Breen D, Cameron D, Jago B, Hall J, Lowe D, Innes J, Tanzer J, Chadwick V, Thompson L, Gorman K, Simmons M, Barnett B, Sampson K, De'Ath G, Mapstone B, Marsh H, Possingham H, Ball I, Ward T, Dobbs K, Aumend J, Slater D, and Stapleton K. 2005. Establishing no-take areas in the Great Barrier Reef: large-scale implementation of theory on marine protected areas. Conservation Biology, 19(6): 1733-1744. doi:10.1111/j.15231739.2005.00302.x.

Fox HE, Christian C, Nordby JC, Pergams ORW, Peterson GD, and Pyke CR. 2006. Perceived barriers to integrating social science and conservation. Conservation Biology, 20(6): 1817-1820. doi:10.1111/ j.1523-1739.2006.00598.x.

Freitag A. 2014. Naming, framing, and blaming: exploring ways of knowing in the deceptively simple question “what is water quality?" Human Ecology, 42(2): 325-337. doi:10.1007/s10745-014-9649-5.

Garrett-Jones S. 2009. Transdisciplinarity and disciplinarity in the university of the future. In Unity of knowledge in transdisciplinary research for sustainable development volume II. Edited by G Hirsch Hadorn. EOLSS Publishers Co. Ltd., Oxford, United Kingdom. pp. 191-210.

Gewin V. 2014. Interdisciplinary research: break out. Nature, 511(7509): 371-373. doi:10.1038/ nj7509-371a.

Gibbs J, Hunter M, and Sterling EJ. 2008. Problem-solving in conservation biology and wildlife management.2nd edition. Blackwell Publishing, Malden, MA. 344 p.

Greenwood JD. 2003. The monitoring of British breeding birds: a success story for conservation science? Science of the Total Environment, 310(1-3): 221-230. doi:10.1016/S0048-9697(02) 00642-3.

Griggs D, Stafford-Smith M, Gaffney O, Rockström J, Öhman MC, Shyamsundar P, Steffen W, Glaser G, Kanie N, and Noble I. 2013. Policy: sustainable development goals for people and planet. Nature, 495(7441): 305-307. doi:10.1038/495305a. 
Gupta N, Bower SD, Raghaven R, Danylchuk AJ, and Cooke SJ. 2015. Status of recreational fisheries in India: development, issues, and opportunities. Reviews in Fisheries and Aquaculture, 23(3): 291-301. doi:10.1080/23308249.2015.1052366.

Haapasaari P, Kulmala S, and Kuikka S. 2012. Growing into interdisciplinarity: how to converge biology, economics, and social science in fisheries research? Ecology and Society, 17(1): 6. doi:10.5751/ ES-04503-170106.

Hadorn GH, Bradley D, Pohl C, Rist S, and Wiesmann U. 2006. Implications of transdisciplinarity for sustainability research. Ecological Economics, 60(1): 119-128. doi:10.1016/j.ecolecon.2005.12. 002.

Hooper DU, Adair EC, Cardinale BJ, Byrnes JEK, Hungate BA, Matulich KL, Gonzales A, Duffy JE, Gamfeldt L, and O'Connor MI. 2012. A global synthesis reveals biodiversity loss as a major driver of ecosystem change. Nature, 486(7401): 105-108. doi:10.1038/nature11118.

Huntington H. 2000. Using traditional ecological knowledge in science: methods and applications. Ecological Applications, 10(5):1270-1274. doi:10.1890/1051-0761(2000)010[1270:UTEKIS]2. $0 . \mathrm{CO} ; 2$.

Kareiva P, and Marvier M. 2012. What is conservation science? BioScience, 62(11): 962-969. doi:10.1525/bio.2012.62.11.5.

Keppel G, Morrison C, Watling D, Tuiwawa MV, and Rounds IA. 2012. Conservation in tropical Pacific Island countries: why most current approaches are failing. Conservation Letters, 5(4): 256-265. doi:10.1111/j.1755-263X.2012.00243.x.

Klein JT. 2000. A conceptual vocabulary of interdisciplinary science. In Practising interdisciplinarity. Edited by $\mathrm{P}$ Weingart and N Stehr. University of Toronto Press, Toronto, ON. pp. 3-24.

Kockelmans JJ. 1979. Why interdisciplinarity? In Interdisciplinarity and higher education. Edited by JJ Kockelmans. Penn State Press, University Park, PA. pp. 123-160.

Kurland NB, Michaud KE, Best M, Wohldmann E, Cox H, Pontikis K, and Vasishth A. 2010. Overcoming silos: the role of an interdisciplinary course in shaping a sustainability network. Academy of Management Learning and Education, 9(3): 457-476. doi:10.5465/ AMLE.2010.53791827.

Landon AC, van Riper CJ, Anjeli NF, Fitzgerald DB, and Neam KD. 2015. Growing transdisciplinary roots in the Peruvian Amazon: lessons from the field. The Journal of Transdisciplinary Environmental Studies, 14(1): 2-12.

Lélé S, and Norgaard RB. 2005. Practicing interdisciplinarity. BioScience, 55(11): 967-975. doi:10.1641/0006-3568(2005)055[0967:PI]2.0.CO;2.

Liu J, Dietz T, Carpenter SR, Alberti M, Folke C, Moran E, Pell AN, Deadman P, Kratz T, Lubchenco J, Ostrom E, Ouyang Z, Provencher W, Redman CL, Schneider SH, and Taylor WW. 2007. Complexity of coupled human and natural systems. Science, 317(5844): 1513-1516. doi:10.1126/ science.1144004.

Liu J, Linderman M, Ouyang Z, An L, Yang J, and Zhang H. 2001. Ecological degradation in protected areas: the case of Wolong Nature Reserve for Giant Pandas. Science, 292(5514): 98-101. doi:10.1126/ science.1058104. 
Liu J, Ouyang Z, Taylor WW, Groop R, Tan Y, and Zhang H. 1999. A framework for evaluating the effects of human factors on wildlife habitat: the case of Giant Pandas. Conservation Biology, 13(6): 1360-1370. doi:10.1046/j.1523-1739.1999.98418.x.

Luks F, and Siebenhüner B. 2007. Transdisciplinarity for social learning? The contribution of the German socio-ecological research initiative to sustainability governance. Ecological Economics, 63(2-3): 418-426. doi:10.1016/j.ecolecon.2006.11.007.

Lynch J. 2006. It's not easy being interdisciplinary. International Journal of Epidemiology, 35(5): 1119-1122. doi:10.1093/ije/dyl200.

Mallegowda P. 2013. Interdisciplinary research: way forward for biodiversity conservation. Current Science, 105(9): 1202-1203.

Mascia MB, Brosius JP, Dobson TA, Forbes BC, Horowitz L, McKean MA, and Turner NJ. 2003. Conservation and the social sciences. Conservation Biology, 17(3): 649-650. doi:10.1046/ j.1523-1739.2003.01738.x.

Max-Neef MA. 2005. Foundations of transdisciplinarity. Ecological Economics, 53(1): 5-16. doi:10.1016/j.ecolecon.2005.01.014.

Meffe GK, and Viederman S. 1995. Combining science and policy in conservation biology. Wildlife Society Bulletin, 23(3): 327-332.

Metzger N, and Zare RN. 1999. Interdisciplinary research: from belief to reality. Science, 283(5402): 642-643. doi:10.1126/science.283.5402.642.

Miller BW, Caplow SC, and Leslie PW. 2012. Feedbacks between conservation and social-ecological systems. Conservation Biology, 26(2): 218-227. doi:10.1111/j.1523-1739.2012.01823.x.

Miller RG, Hutchison ZL, Macleod AK, Burrows MT, Cook EJ, Last KS, and Wilson B. 2013. Marine renewable energy development: assessing the Benthic Footprint at multiple scales. Frontiers in Ecology and the Environment, 11(8): 433-440. doi:10.1890/120089.

Miller TR, Baird TD, Littlefield CM, Kofinas G, Chapin FS, and Redman CL. 2008. Epistemological pluralism: reorganizing interdisciplinary research. Ecology and Society, 13(2): 46.

Naeem S. 2002. Ecosystem consequences of biodiversity loss: the evolution of a paradigm. Ecology, 83(6): 1537-1552. doi:10.1890/0012-9658(2002)083[1537:ECOBLT]2.0.CO;2.

Naiman RJ. 1999. A perspective on interdisciplinary science. Ecosystems, 2(4): 292-295. doi:10.1007/ s100219900078.

Pooley SP, Mendelsohn JA, and Milner-Gulland EJ. 2014. Hunting down the chimera of multiple disciplinarity in conservation science. Conservation Biology, 28(1): 22-32. doi:10.1111/cobi.12183.

Regan HM, Ben-Haim Y, Langford B, Wilson WG, Lundberg P, Andelman SJ, and Burgman MA. 2005. Robust decision-making under severe uncertainty for conservation management. Ecological Applications, 15(4): 1471-1477. doi:10.1890/03-5419.

Reyers B, Roux DJ, Cowling RM, Ginsburg AE, Nel JL, and O’Farrell P. 2010. Conservation planning as a transdisciplinary process. Conservation Biology, 24(4): 957-965. doi:10.1111/j.15231739.2010.01497.x. 
Rhoten D, and Parker A. 2004. Risks and rewards of an interdisciplinary research path. Science, 306(5704): 2046. doi:10.1126/science.1103628.

Rittel HWJ, and Webber MM. 1973. Dilemmas in a general theory of planning. Policy Sciences, 4(2): 155-169. doi:10.1007/BF01405730.

Roy ED, Morzillo AT, Seijo F, Reddy SMW, Rhemtulla JM, Milder JC, Kuemmerle T, and Martin SL. 2013. The elusive pursuit of interdisciplinarity at the human-environment interface. BioScience, 63(9): 745-753. doi:10.1093/bioscience/63.9.745.

Sandbrook C, Adams WM, Büscher B, and Vira B. 2013. Social research and biodiversity conservation. Conservation Biology, 27(6): 1487-1490. doi:10.1111/cobi.12141.

Schäfer RB, Cooke SJ, Arlinghaus R, Bonada N, Brischoux F, Casper AF, Catford JA, and Rolland V. 2011. Perspectives from early career researchers on the publication process in ecologya response to Statzner \& Resh (2010). Freshwater Biology, 56: 2405-2412. doi:10.1111/j.13652427.2011.02673.x.

Soulé ME. 1985. What is conservation biology?: A new synthetic discipline addresses the dynamics and problems of perturbed species, communities, and ecosystems. BioScience, 35(11): 727-734. doi:10.2307/1310054.

Steffen W, Crutzen PJ, and McNeill JR. 2007. The Anthropocene: are humans now overwhelming the great forces of nature. AMBIO: A Journal of the Human Environment, 36(8): 614-621. doi:10.1579/ 0044-7447(2007)36[614:TAAHNO]2.0.CO;2.

Stock P, and Burton RJF. 2011. Defining terms for integrated (multi-inter-trans-disciplinary) sustainability research. Sustainability, 3(8): 1090-1113. doi:10.3390/su3081090.

Strang V. 2009. Integrating the social and natural sciences in environmental research: a discussion paper. Environment, Development and Sustainability, 11: 1-18. doi:10.1007/s10668-007-9095-2.

Sutherland WJ, Gardner TA, Haider LJ, and Dicks LV. 2014. How can local and traditional knowledge be effectively incorporated into international assessments? Oryx, 48(1): 1-2. doi:10.1017/ S0030605313001543.

Sutherland WJ, Pullin AS, Dolman PM, and Knight TM. 2004. The need for evidence-based conservation. Trends in Ecology \& Evolution, 19(6): 305-308. doi:10.1016/j.tree.2004.03.018.

Tress G, Tress B, and Fry G. 2005. Clarifying integrative research concepts in landscape ecology. Landscape Ecology, 20(4): 479-493. doi:10.1007/s10980-004-3290-4.

Vitousek PM, Mooney HA, Lubchenco J, and Melillo JM. 1997. Human domination of Earth's ecosystems. Science, 277(5325): 494-499. doi:10.1126/science.277.5325.494.

Walters CJ, and Holling CS. 1990. Large-scale management experiments and learning by doing. Ecology, 71(6): 2060-2068. doi:10.2307/1938620.

Zalasiewicz J, Williams M, Haywood A, and Ellis M. 2011. The Anthropocene: a new epoch of geological time? Philosophical Transactions of the Royal Society of London A: Mathematical, Physical and Engineering Sciences, 369(1938): 835-841. doi:10.1098/rsta.2010.0339. 